\title{
Correction to: Effect of Multipass FSP on Si-Rich TIG Welded Joint of Dissimilar Aluminum Alloys AA8011-H14 and AA5083-H321: EBSD and Microstructural Evolutions
}

\author{
Abdellah Nait Salah ${ }^{1} \cdot$ Sipokazi Mabuwa ${ }^{2} \cdot$ Husain Mehdi $^{3} \cdot$ Velaphi Msomi $^{2} \cdot$ Mohammed Kaddami $^{1}$. \\ Prabhujit Mohapatra ${ }^{4}$
}

Published online: 7 March 2022

(C) Springer Nature B.V. 2022

\section{Correction to: Silicon}

https://doi.org/10.1007/s12633-022-01717-4

The original version of the article unfortunately contained an error.

A data was inadvertently added in the second author's name Sipokazi Mabuwa. The affiliation footnotes were also incorrect. The correct details are shown above.

The original article has been corrected.

Publisher's Note Springer Nature remains neutral with regard to jurisdictional claims in published maps and institutional affiliations.

The online version of the original article can be found at https://oi.org/ $10.1007 / \mathrm{s} 12633-022-01717-4$

Husain Mehdi

husainmehdi4u@gmail.com

1 Faculty of Science and Technology, Laboratory "Physical Chemistry of Processes and Materials", Hassan First University of Settat, Settat, Morocco

2 Mechanical Engineering Department, Cape Peninsula University of Technology, P.O. Box 1906, Bellville 7535, South Africa

3 Department of Mechanical Engineering, Delhi Technological University, Delhi, India

4 School of Advanced Sciences, VIT University, Vellore, India 